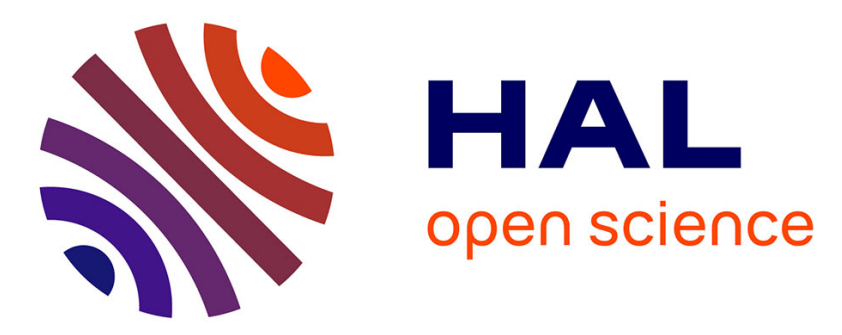

\title{
Dynamic Analysis of Urban Landscape Patterns of Vegetation Coverage Based on Multi-temporal Landsat Dataset
}

Dong Liang, Ling Teng, Linsheng Huang, Xinhua Xie, Yan Zuo, Jingling Zhao

\section{- To cite this version:}

Dong Liang, Ling Teng, Linsheng Huang, Xinhua Xie, Yan Zuo, et al.. Dynamic Analysis of Urban Landscape Patterns of Vegetation Coverage Based on Multi-temporal Landsat Dataset. 9th International Conference on Computer and Computing Technologies in Agriculture (CCTA), Sep 2015, Beijing, China. pp.300-316, 10.1007/978-3-319-48357-3_30 . hal-01557852

\section{HAL Id: hal-01557852 \\ https://hal.inria.fr/hal-01557852}

Submitted on 6 Jul 2017

HAL is a multi-disciplinary open access archive for the deposit and dissemination of scientific research documents, whether they are published or not. The documents may come from teaching and research institutions in France or abroad, or from public or private research centers.
L'archive ouverte pluridisciplinaire HAL, est destinée au dépôt et à la diffusion de documents scientifiques de niveau recherche, publiés ou non, émanant des établissements d'enseignement et de recherche français ou étrangers, des laboratoires publics ou privés.

\section{(c)(1)}

Distributed under a Creative Commons Attribution| 4.0 International License 


\title{
Dynamic Analysis of Urban Landscape Patterns of Vegetation Coverage Based on Multi- temporal Landsat Dataset
}

\author{
Dong Liang ${ }^{1, \mathrm{a}}$, Ling Teng ${ }^{1, \mathrm{~b}}$, Linsheng Huang ${ }^{1, \mathrm{c}}$, Xinhua Xie $^{1, \mathrm{~d}}$, Yan Zuo ${ }^{1, \mathrm{e}}$ and \\ Jingling Zhao ${ }^{1,}$ \\ ${ }^{1}$ Key Laboratory of Intelligent Computing \& Signal Processing, Ministry of Education, Anhui \\ University, Hefei 230601, China; \\ adliang@ahu.edu.cn, ${ }^{\mathrm{b}} 695805968 @ q q . c o m,{ }^{c}$ linsheng0808@163.com, \\ dxiexinhuavip@163.com, ${ }^{\mathrm{e}} 872026319 @ q q . c o m,{ }^{\mathrm{f}}$ aling0123@163.com
}

\begin{abstract}
Dynamic monitoring of vegetation coverage changes, especially on a relatively large temporal scale, have important practical significance in urban planning and environmental protection. The objective of this study is to dynamically investigate the urban landscape patterns of vegetation coverage based on remote sensing techniques. Multi-temporal Landsat images of 1990, 2000 and 2013 were firstly used to produce three vegetation coverage maps of Hefei City, Anhui Province, China with five grades using the NDVI (Normalized Difference Vegetation Index) dimidiate pixel model. Subsequently, a total of eight landscape pattern indictors in FRAGSTATS 4.2 were selected to analyze the dynamic characteristics of area, quantity and density for the study area with different vegetation coverage grades. The results showed that 1) the dominant vegetation coverage of 1990, 2000 and 2013 were the high vegetation coverage, the moderate vegetation coverage and the moderate-to-high vegetation coverage, respectively. The acreage of non-vegetation coverage increased by $1.89 \%$, while the high vegetation coverage decreased by $10.48 \%$ from 1990 to $2013 ; 2$ ) the quantity and density of patches decreased by $33.42 \%$ and $33.41 \%$ during 1990-2013. Shannon's diversity index and Shannon's evenness index increased from 0.92 in 1990 to 0.97 in 2000, and then declined to 0.96 in 2013; and 3) the contagion index had an upward trend and conversely the aggregation index showed no significant changes, but both of them were close to 1 during 1990-2013. In comparison with natural influences, the primary driving forces causing the changes were ascribed to human factors including the rapid population growth and fast-growing urban areas.
\end{abstract}

Keywords: landscape pattern, vegetation coverage, normalized difference vegetation index (NDVI), Landsat, remote sensing.

\section{Introduction}

Vegetation is a general term that describes the phytocoenosium covering the land, which not only provides large amount of material resources (e.g., vegetation products and vegetation by-product), but also helps in maintaining soil and water, conserving water, fixing sand, purifying air, regulating climate and so on. Furthermore, it plays 
an important role in maintaining the ecological balance and promoting regional sustainable development [1-3]. With the continuous improvement of socio-economics, the built-up areas gradually expanded, and spatial regions are becoming more concentrated due to human activities, especially in urban areas. Consequently, quantitative monitoring of the spatio-temporal changes of urban vegetation cover has attracted more attention in urban planning and environmental protection [4-5]. In traditional vegetation monitoring, statistical methods with lower updating frequency are usually used, but they are rather time-consuming, laborious, and costly, especially failing to monitor the changes of vegetation coverage on a large scale. Conversely, remote sensing has facilitated extraordinary advances in analyzing urban vegetation coverage changes by its real-time and wide coverage features, which has become a significant measurement for monitoring the urban ecological environment.

In recent years, different ecological problems have appeared in urban regions, and some landscape ecology approaches to combining remote sensing have been applied to explore the urban landscape pattern and its change process [6-9]. Tang et al. linked spatial pattern and biophysical parameters of urban vegetation by multi-temporal Landsat imagery [10]. Liu et al. monitored vegetation cover changes in Hefei based on normalized difference vegetation index (NDVI) dimidiate pixel model [11]. Deng et al. used MODIS-NDVI to monitor the vegetation coverage of Shangri La in Northwest Yunnan [12]. It can be found that in the previous studies, multi-temporal Landsat imagery including $\mathrm{TM}$ and $\mathrm{ETM}^{+}$were primarily used on a regional scale, while MODIS-NDVI products were mainly used on a national or continental scale. In addition, the methods used in the studies were primarily concentered on how to calculate the vegetation coverage precisely for monitoring the spatio-temporal vegetation changes. Conversely, the urban landscape patterns of vegetation coverage have not fully been investigated and explored. Specifically, two primary limitations can be found in the aforementioned studies. On the one hand, most of the studies are based on the changes in vegetation quantity and spatial distribution derived from remote sensing imagery. On the other hand, most remote sensing data are focused on Landsat $\mathrm{TM} / \mathrm{ETM}^{+}$(before 2010) and didn't integrate the new data of Landsat8 launched in 2013.

In this study, Hefei, the capital city of Anhui Province, China were taken as the study area and three Landsat imageries (Landsat 5 TM images of 1990 and 2000 and Landsat 8 OLI (Operational Land Imager) image of 2013) were firstly used to calculate and classify the urban vegetation coverage grades based on the NDVI dimidiate pixel model., Subsequently, the landscape patterns of vegetation coverage were dynamically analyzed in FRAGSTATS 4.2 software. Finally, the primary driving forces were also investigated.

\section{Data and Methodology}

\subsection{Study Area}

$\mathrm{Hefei}_{2}$ the capital city of Anhui Province, China is located between $30^{\circ} 56^{\prime} \mathrm{N}$ $32^{\circ} 32^{\prime} \mathrm{N}$ and $116^{\circ} 40^{\prime} \mathrm{E}-117^{\circ} 58^{\prime} \mathrm{E}$, with an area of more than $11408.48 \mathrm{~km}^{2}$. It has a 
subtropical monsoon climate, with an annual average temperature of $15.7^{\circ} \mathrm{C}$, an annual average precipitation of $1000 \mathrm{~mm}$ and an annual average sunshine of 2100 hours. As of 2014, the city has a total resident population of 7.696 million. The general trend of topography is high in the north, southeast and southwest, and low in central and southern parts.

\subsection{Data Source and Pre-Processing}

Landsat (name indicating Land+ Satellite) imagery is available since 1972 from seven satellites in the Landsat series, especially the newly launched Landsat8 in 2013. The time-series remotely sensed imagery with various spectral and spatial resolutions in Landsat series provides good data sources for dynamic analysis of urban vegetation coverage. In this study, multi-temporal Landsat satellite images were acquired and used to dynamically investigate the landscape pattern changes of urban vegetation coverage. Specifically, the cloud-free Landsat5 TM data (path 121/row 38) of 1990 and 2000 and Landsat 8 OLI image of 2013 were acquired (Table 1 and Figure 1), where the data of 2000 and 2013 was derived from the United States Geological Survey (USGS), and the data of 1990 was derived from the Global Land Cover Facility (GLCF). In addition, the vector data of Hefei was also used to mask the three Landsat images.

Table 1. Multi-temporal Landsat images used in the study

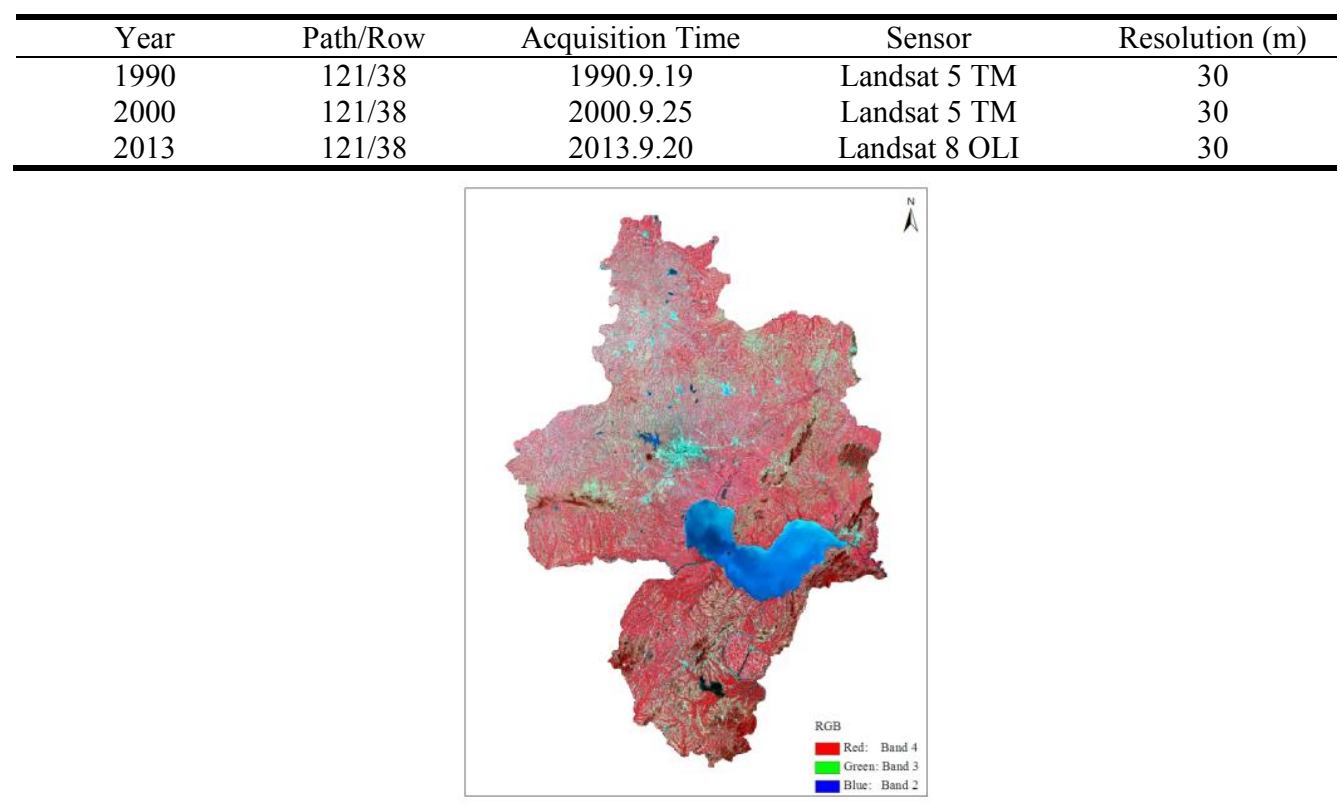


(a) 1990

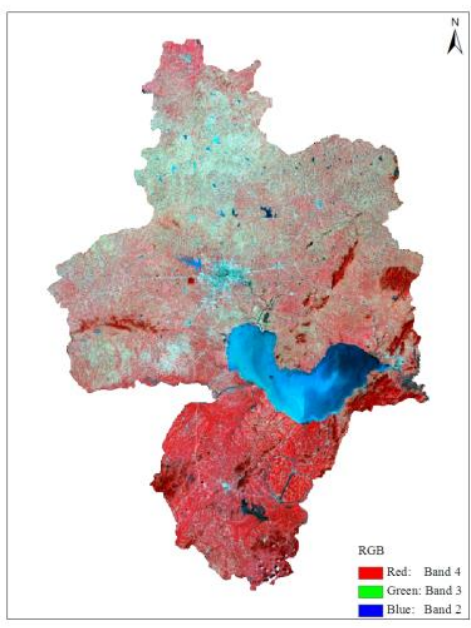

(b) 2000

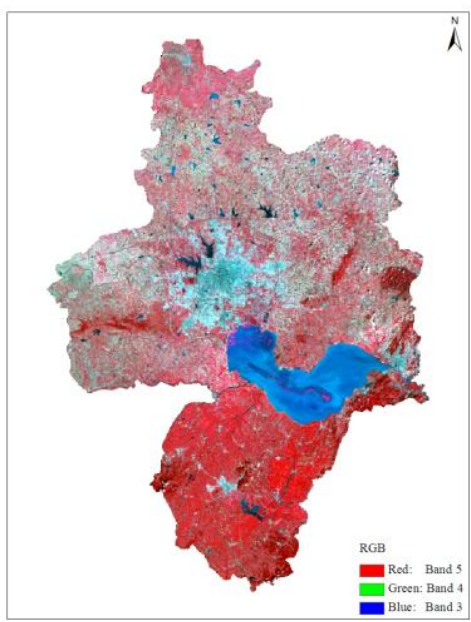

(c) 2013

Fig. 1. The false-color composite images of 1990, 2000 and 2013 of Hefei

The Landsat_5 TM_in 1990 derived from the GLCF is the Geocover data set which is a collection of high resolution satellite imagery provided in a standardized, orthorectified format. . While the Landsat_5 TM in 2000 and Landsat_8 OLI in 2013 derived from the USGS are primary products and they were processed by referring to the data of 1990. The quadratic polynomial geometric correction model was used to geometrically correct the images of 2000 and 2013 within 0.5 pixels. Radiometric calibration and atmospheric correction were also performed. Finally, the vector file of Hefei was utilized to mask the three images. 


\subsection{Method}

As shown in Figure 2, two primary steps would be required. Firstly, the NDVI images of three pre-processed images were respectively calculated according to the Eq. 1. Then, the appropriate values of $N D V I_{\text {veg }}$ and $N D V I_{\text {soil }}$ for three periods were selected from corresponding Landsat images, and the vegetation coverage were calculated in accordance with the Eq. 2. Finally, different landscape indices were calculated in FRAGSTATS 4.2 software for further analyzing the vegetation landscape patterns in the study area.

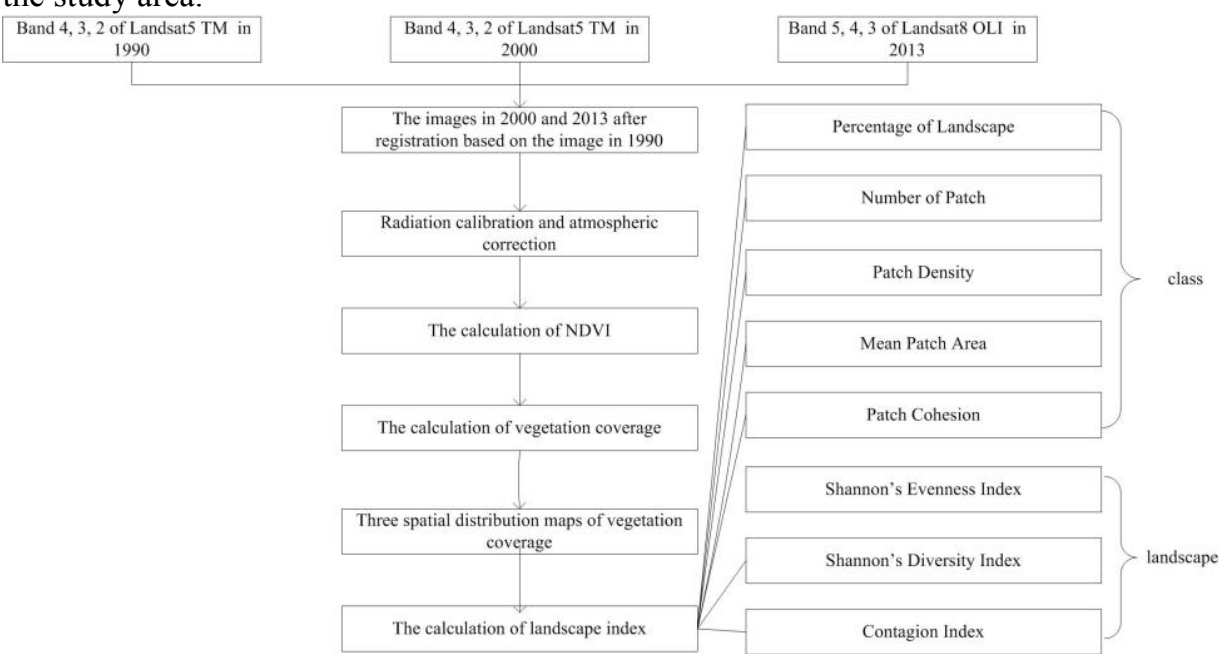

Fig. 2. Flow chart of calculating vegetation coverage and performing landscape pattern analysis

\subsubsection{Calculation of NDVI}

Vegetation index (VI) can show a strong absorption characteristics of plant chlorophyll in $0.69 \mu \mathrm{m}$. Consequently, the vegetation healthy status can be expressed by corresponding spectral information of red and near infrared bands by simple linear or non-linear combination. Multi-spectral remote sensing data have been extensively used to investigate the vegetation features based on different vegetation indices [13]. In comparison with other VIs, NDVI (Eq.1) has been widely used in the monitoring of vegetation biomass by remote sensing_techonology. It is not only related to the plant distribution density, but also reflects the plant growth and the spatial distribution density of plant growth factors $[14,15]$.

$$
N D V I=\frac{\rho_{N I R}-\rho_{r e d}}{\rho_{N I R}+\rho_{r e d}}
$$

Where, $\rho_{\text {NIR }}$ and $\rho_{\text {red }}$ represent the reflectance of the near infrared (NIR) band and the red band. For the Landsat $5 \mathrm{TM}$ image, NIR corresponds to the Band 4 and red corresponds to the Band 3. For the Landsat 8 OLI image, they correspond to the Band 5 and the Band 4, respectively. 


\subsubsection{Calculation of Vegetation Coverage}

Vegetation coverage refers to the ratio of the vegetation canopy area in vertical projection and the total soil area, namely planting soil ratio [16]. In our study, and the NDVI dimidiate pixel model was selected to estimate the vegetation coverage (Eq.2), which is a simple and practical remote sensing estimation model by assuming that the earth's surface corresponding to the pixel is composited by the vegetation cover regions and non-vegetation regions [17-18]. Similarly, the observed spectral information by remote sensing sensor is also composited by the linear weighted synthesis of the two components, and the weight of each factor is the proportion of the pixel area [15].

$$
F_{c}=\frac{N D V I-N D V I_{\text {soil }}}{N D V I_{v e g}-N D V I_{\text {soil }}}
$$

Where, $F_{c}$ represents the vegetation coverage, while $N D V I_{\text {veg }}$ and $N D V I_{\text {soil }}$ were the $N D V I$ values of pure vegetation and pure soil, respectively.

\subsubsection{Selection and Calculation of Landscape Pattern Indices}

Landscape indices are usually used in landscape ecology quantitative research methods, which can describe the landscape patterns and corresponding changes, and establish a link between the landscape pattern and changing process [19]. In this study, | the landscape indices were calculated in FRAGSTATS_4.2 software which can provide more than 50 landscape indices at three levels (patches, landscape types and landscape). A total of eight classes can be divided according to the measurement aspects of landscape pattern, which are Area/Density/Edge Index, Shape Index, Core Area Index, Independent/Near Index, Contrast Index, Contagion/Discrete Degree Index, Connectivity Index and Diversity Index. Specifically, two aspects of landscape patterns were mainly carried out. One is the amount distribution of patches of different vegetation coverage grades to describe the structure and changes, which includes Number of Patch (NP), Patches Area (AREA), Aggregation Index (AI), Percentage of Landscape (PLAND), Shannon's Evenness Index (SHEI), Shannon's Diversity Index (SHDI), etc. The other is the spatial form and distribution characteristics of patches for describing spatial pattern and changes, which are measured by Contagion Index (CONTAG), Fractal Dimension Index (FRAC), Patch Cohesion Index (COHESION), etc. [20]. In our study, PLAND, NP, PD, AREA-MN, COHESION, CONTAG, SHDI and SHEI were selected by referring to [21] to describe the vegetation spatial pattern changes (Table 2).

Table 2. Landscape pattern indices and their ecological significance *

\begin{tabular}{cll}
\hline Index and formula & Level & \multicolumn{1}{c}{ Ecological significance } \\
\hline PLAND $=p_{i}$ & Landscape & Reflecting the abundance \\
& ratio of a certain type of \\
& class & patches in the landscape. \\
\hline
\end{tabular}




$$
\begin{aligned}
& N P=n_{i} \\
& P D=\frac{\mathrm{n}_{i}}{A} * 10000 * 100 \\
& A R E A-M N=\frac{\sum_{j=1}^{n} x_{i j}}{n_{i}} \\
& \text { COHESION }=\left[1-\frac{\sum_{i=1}^{m} \sum_{j=1}^{n} p_{i j}}{\sum_{i=1}^{m} \sum_{j=1}^{n} p_{i j} \sqrt{a_{i j}}}\right] \text { class } \\
& \text { CONTAG }=\left[1+\sum_{i=1}^{m} \sum_{j=1}^{n} \frac{p_{i j} \ln \left(p_{i j}\right)}{2 \ln (\mathrm{m})}\right] \quad \text { Landscape } \\
& S H D I=-\sum_{i=1}^{m}\left(\mathrm{p}_{i} \cdot \ln \mathrm{p}_{i}\right) \\
& S H E I=\frac{-\sum_{i=1}^{m}\left(\mathrm{p}_{i} \cdot \ln \left(\mathrm{p}_{i}\right)\right)}{\ln m}
\end{aligned}
$$

\section{Reflecting of the reunion}

Landscape

* denotes that $i$ represents the patch type; $j$ represents the amount of patches; $\mathrm{m}$ represents the total number of all the patch types; $n$ represents the number of a certain patch type; $\mathrm{P}_{i}$ represented the circumference of the $i$ th patch type.

\section{Results and Discussion}




\subsection{Classification Maps of Vegetation Coverage}

Three vegetation coverage maps were produced according to the Eq. 2 (Fig.3). Five grades were categorized: Grade 1: non-vegetation coverage $\left(0 \leq F_{c}<20\right)$; Grade 2: low vegetation coverage $\left(20 \leq F_{c}<40\right)$; Grade 3: moderate vegetation coverage $\left(40 \leq F_{c}<60\right)$; Grade 4: moderate-to-high vegetation coverage $\left(60 \leq F_{c}<80\right)$; and Grade 5: high vegetation coverage $\left(80 \leq F_{c}<100\right)$. It showed that the spatial distribution of vegetation coverage in Hefei showed an obvious characteristics, The peripheral vegetation coverage was higher and the central city was lower in 1990, 2000 and 2013. In 1990, the vegetation coverage of the study area was good, the high vegetation coverage was mainly in the south, southwest and northeast of, and the area of non-vegetation coverage was mainly concentrated in the central city. From 1990 to 2013, the vegetation coverage of the study area had been reduced obviously. The high vegetation coverage in southwest and northeast had been degraded into low and moderate-to-high vegetation coverage and the area of nonvegetation coverage in the central city showed an obvious trend of expanding. The regions with obvious decreasing vegetation coverage can be ascribed to active regional economic developments [13]. On the other hand, the changed vegetation coverage regions can also reflect the development paths for the study area. In general, the urban sprawl has been transferred from central urban area to the periphery.

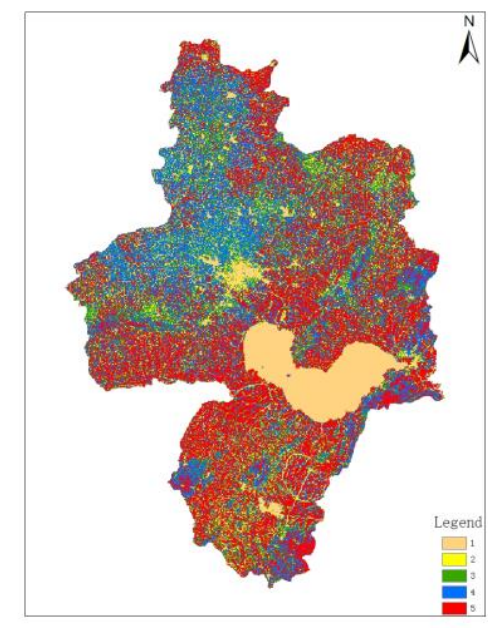


(a) 1990

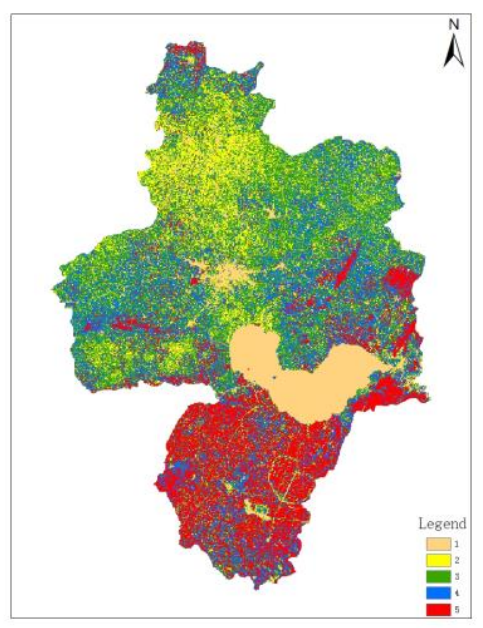

(b) 2000

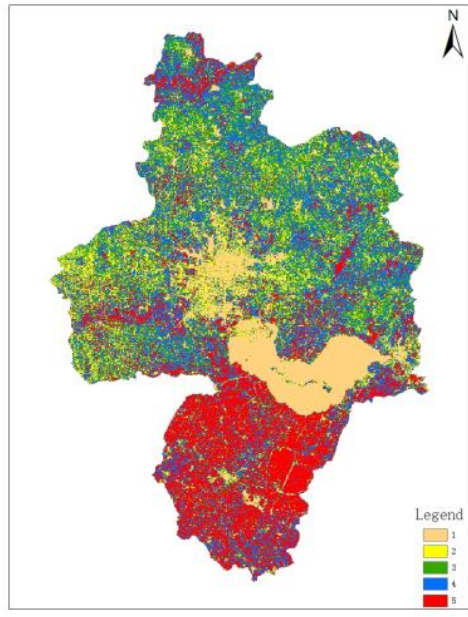

(c) 2013

Fig. 3. Three spatial distribution maps of five-grade vegetation coverage

\subsection{Analysis of the Number of Vegetation Landscape Structure Change}

The Percentage of Landscape (PLAND), Number of Patches (NP), Shannon's Diversity Index (SHDI) and Shannon's Evenness Index (SHEI) were selected to 
analyze the changes of the number of vegetation landscape structure. As shown in Table 3, the percentage distribution (Figure 4 a) of different vegetation coverage of 1990, 2000 and 2013 could be obtained. In 1990, Grade 5 occupied the dominant position in the landscape, and followed by Grade 4, Grade 3, Grade 1 and Grade 2. In 2000 , Grade 3 occupied the dominant position in the landscape, and the area ratio of Grade 5 was relatively high. In 2013, Grade 4 was the dominant type in the landscape. The area ratio of Grade 1 increased slightly from $12.35 \%$ to $14.25 \%$ during 1990 2013. The area ratio of Grade 2 increased from $8.25 \%$ to $13.90 \%$ during $1990-2000$, and then declined to $10.89 \%$ in 2013 . The area ratio of Grade 3 increased from $15.54 \%$ to $27.61 \%$ during $1990-2000$, and then declined to $21.18 \%$ in 2013 . On the whole, the area of Grade 2 and Grade 3 increased by $2.64 \%$ and $5.64 \%$ respectively during 1990-2013. The area of Grade 4 increase slightly from $28.36 \%$ to $28.67 \%$. Conversely, the area of Grade 5 changed greatly and decreased from $35.50 \%$ to $25.02 \%$ during 1990-2013.

To describe the landscape heterogeneity and fragmentation, the number of patches was used. As shown in Table 3, the distribution of the number of patches for different vegetation coverage grades could be also obtained (Figure $4 \mathrm{~b}$ ). It showed that the total number of patches in the study area reduced by 278555 during 19902013. Specifically, the number of patches of Grade 1 increased from 74867 to 74908 during 1990-2000, and then decreased to 47698 in 2013. From 1990 to 2013, that of Grade 2 and Grade 5 decreased by 42237 and 8497, respectively. That of Grade 3 and Grade 4 decreased from 259384 to 170252 and from 215976 to 183300 respectively during 1990-2000, and then decreased by 12546 and 66298. It was obvious that the number of patch of Grade 3 changed greatly during 1990-2013 (Figure 4).

The increase of Shannon's Diversity Index indicated that various types of patches in the landscape showed the equalized distribution. Larger evenness index showed that the landscape patches in area had more uniform distribution. The results showed that SHDI and SHEI were relatively high in the study area. The Shannon's Diversity Index increased from 1.4785 to 1.5526 and the Shannon's Evenness Index increased from 0.9186 to 0.9647 during $1990-2013$.

Table 3. Spatial landscape pattern properties of vegetation coverage

\begin{tabular}{|c|c|c|c|c|c|c|c|c|c|c|c|c|}
\hline \multirow{3}{*}{ Type } & \multirow{2}{*}{\multicolumn{3}{|c|}{$\begin{array}{c}\text { Percentage of landscape } \\
(\%) \\
\text { PLAND }\end{array}$}} & \multirow{2}{*}{\multicolumn{3}{|c|}{$\begin{array}{c}\text { Patches number (a) } \\
\text { NP }\end{array}$}} & \multirow{2}{*}{\multicolumn{3}{|c|}{$\begin{array}{c}\text { Shannon's Diversity Index } \\
\text { SHDI }\end{array}$}} & \multirow{2}{*}{\multicolumn{3}{|c|}{$\begin{array}{c}\text { Shannon's Diversity Index } \\
\text { SHEI }\end{array}$}} \\
\hline & & & & & & & & & & & & \\
\hline & 1990 & 2000 & 2013 & 1990 & 2000 & 2013 & 1990 & 2000 & 2013 & 1990 & 2000 & 2013 \\
\hline 1 & 12.35 & 12.28 & 14.25 & 74867 & 74908 & 47698 & & & & & & \\
\hline 2 & 8.25 & 13.90 & 10.89 & 189087 & 198783 & 146850 & & & & & & \\
\hline 3 & 15.54 & 27.61 & 21.18 & 259384 & 170252 & 157706 & 1.4785 & 1.5612 & 1.5526 & 0.9186 & 0.9700 & 0.9647 \\
\hline 4 & 28.36 & 25.75 & 28.67 & 215976 & 183300 & 117002 & & & & & & \\
\hline 5 & 35.50 & 20.46 & 25.02 & 94174 & 112682 & 85677 & & & & & & \\
\hline LAND & 100.00 & 100.00 & 100.00 & 833488 & 739925 & 554933 & 1.4785 & 1.5612 & 1.5526 & 0.9186 & 0.9700 & 0.9647 \\
\hline
\end{tabular}




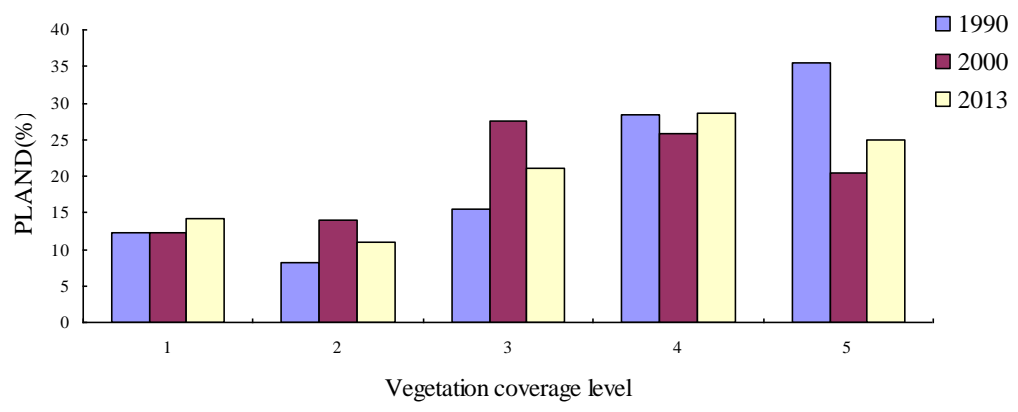

(a) Distribution of PLAND

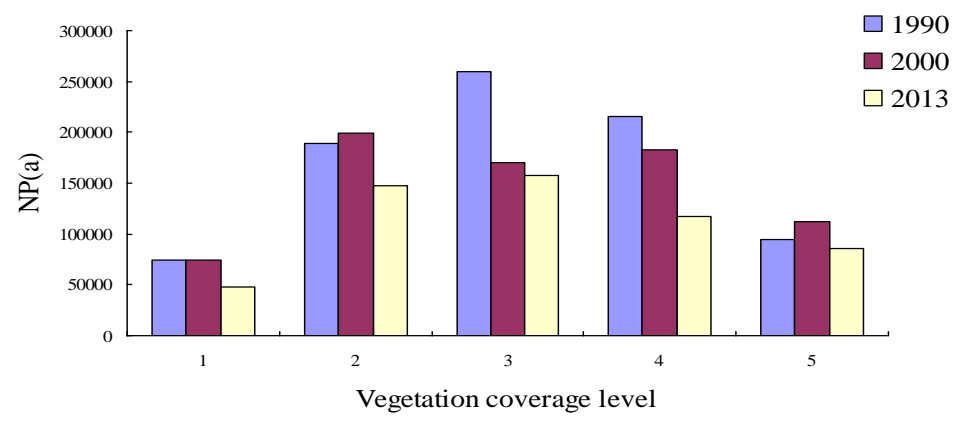

(b) Distribution of NP

Fig. 4. Comparison of PLAND and NP for five vegetation coverage grades among three periods

\subsection{The Changes in Landscape Pattern}

Patch Density Index, Mean Match Area Index, Cohesion Index and Contagion index were selected to analyze the landscape pattern changes in space of different vegetation coverage. As shown in Table 4, patch density distribution of different vegetation coverage of three years could be obtained (Figure 5 a). From 1990 to 2013, the total patch density of landscape in the study area reduced from $72.93 \%$ to $48.56 \%$. For urban areas, patch density decreased at different levels during 1990-2013. For Grade 1, patch density remained unchanged from 1990 to 2000, however it decreased from $6.55 \%$ to $4.17 \%$ during $1990-2013$. For Grade 2 and Grade 5, the patch density increased firstly and then decreased, which showed that patches of two grades were getting less fragmented in the entire period. Similarly, Grade 3 and Grade 4 declined respectively during 1990-2000 and 2000-2013. The largest patch density zones were Grade 3, Grade 2 and Grade 3, respectively. The results could be explained that the lands of the three grades had become more fragmented. Conversely, the smallest patch density zones of three years were the Grade 1, which showed there were lower degree of fragmentation degree in these areas of Grade 1. 
Concerning on the AREAR-MN (Table 3), comparison of the number of patches for different vegetation coverage grades could also be obtained (Figure $5 \mathrm{~b}$ ). There was an increase for all the grades except the Grade 5e. For Grade 1, the mean patch area increased significantly by $1.52 \mathrm{hm}^{2}$, which indicated that the vegetation coverage was fragmentated in the study area during 1990-2013.

From 1990 to 2013, Contagion Index tended to increase and there was no significant changes for Patch Cohesion Index, but both of them were close to 1, which showed that the landscape overall trend gathered, and good natural connectivity. Grade 1, Grade 4 and Grade 5 in the three periods were close to 1, which indicated that the aggregation degree was higher. However, the Patch Cohesion Index of Grade 2 and Grade 3 were relatively lower, which indicated that those regions of three grades had lower degree of aggregation, but they increased for s in 2013.

Table 4. Spatial landscape pattern properties of vegetation coverage

\begin{tabular}{|c|c|c|c|c|c|c|c|c|c|c|c|c|}
\hline \multirow{2}{*}{ type } & \multicolumn{3}{|c|}{$\begin{array}{l}\text { Patch density (\%) } \\
\text { (PD) }\end{array}$} & \multicolumn{3}{|c|}{$\begin{array}{c}\text { Mean patch area }\left(\mathrm{hm}^{2}\right) \\
\text { (AREA-MN) }\end{array}$} & \multicolumn{3}{|c|}{$\begin{array}{c}\text { Patch Cohesion }(\%) \\
\text { (COHESION) }\end{array}$} & \multicolumn{3}{|c|}{$\begin{array}{c}\text { Contagion Index (\%) } \\
\text { (CONTAG) }\end{array}$} \\
\hline & 1990 & 2000 & 2013 & 1990 & 2000 & 2013 & 1990 & 2000 & 2013 & 1990 & 2000 & 2013 \\
\hline 1 & 6.55 & 6.55 & 4.17 & 1.89 & 1.87 & 3.41 & 98.90 & 98.89 & 99.52 & & & \\
\hline 2 & 16.55 & 17.39 & 12.85 & 0.50 & 0.80 & 0.85 & 76.73 & 98.83 & 88.67 & & & \\
\hline 3 & 22.70 & 14.90 & 13.80 & 0.68 & 1.85 & 1.54 & 88.09 & 99.59 & 98.02 & 26.43 & 3.26 & 26.45 \\
\hline 4 & 18.90 & 16.04 & 10.24 & 1.50 & 1.61 & 2.80 & 98.96 & 98.65 & 99.24 & & & \\
\hline 5 & 8.24 & 9.86 & 7.50 & 4.31 & 2.08 & 3.34 & 98.85 & 99.30 & 99.41 & & & \\
\hline LAND & 72.93 & 64.74 & 48.56 & 1.37 & 1.54 & 2.06 & 98.29 & 99.29 & 98.97 & 26.43 & 23.26 & 26.45 \\
\hline
\end{tabular}

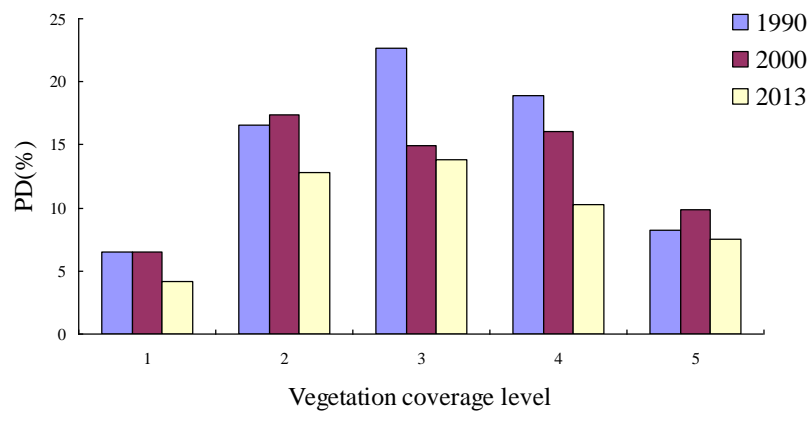

(a) PD

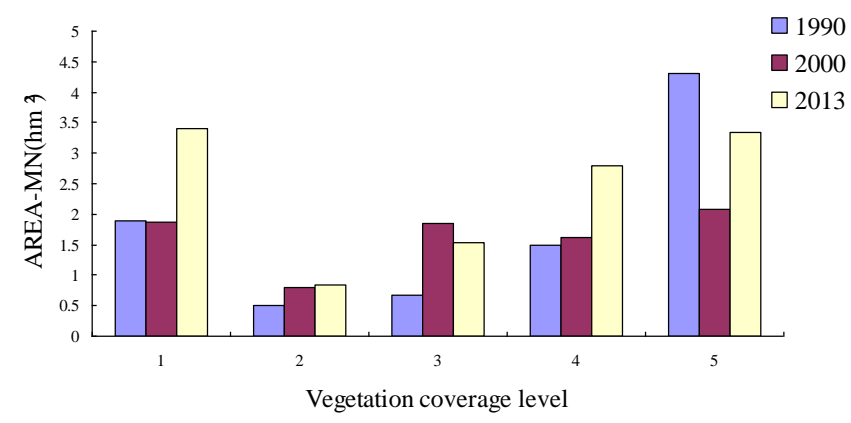


(b) AREA-MN

Fig. 5. Comparison of PD and AREA-MN of for different coverage grades

\subsection{Analysis of Driving Forces}

Driving forces analysis is a way of understanding and accounting for vegetation coverage changes potentially caused by different factors such as regional climate change and human factors [22]. Environmental factors, such as slope, aspect, elevation, temperature, precipitation, etc., usually determine the vegetation growth and agricultural development in the fragile ecosystem [23]. Conversely, Hefei city is the capital city and the influences of human factors paly a highly significant role in changing the vegetation coverage in comparison with regional climate change. Fastgrowing urban areas have changed the natural vegetation coverage, and demographic and economic development are the primary driving factors for the growing metropolitan cities [24]. In this study, three driving forces were investigated including the rapid population growth, the fast-growing urban the higher urbanization level.

\subsubsection{Economic Development}

The urban sprawl for a fast-growing city is substantially driven by the urgent requirements of social and economic development. Consequently, the natural vegetation coverage is changed to adapt to the human activities. Hefei has experienced a remarkable period of rapid economic growth spanning in more than 20 years from 1978 to 2010 (Figure 6). In 1990, the local gross domestic product (GDP) was just 58.19 (100 million) Yuan, but it had increased to 324.73 (100 million) of 2000 and 4672.91 (100 million) of 2013. Similarly, the GDP per capita also showed a rapid growth trend. It was 458, 7481 and 61555 Yuan in 1990, 2000, 2013, respectively. In more than 20 years, the GDP in Hefei had increased by $7,930 \%$ and the GDP per capita have greatly increased by $13340 \%$. It was inevitable that the natural vegetation coverage had been extremely change along with the improvement in economic development. 


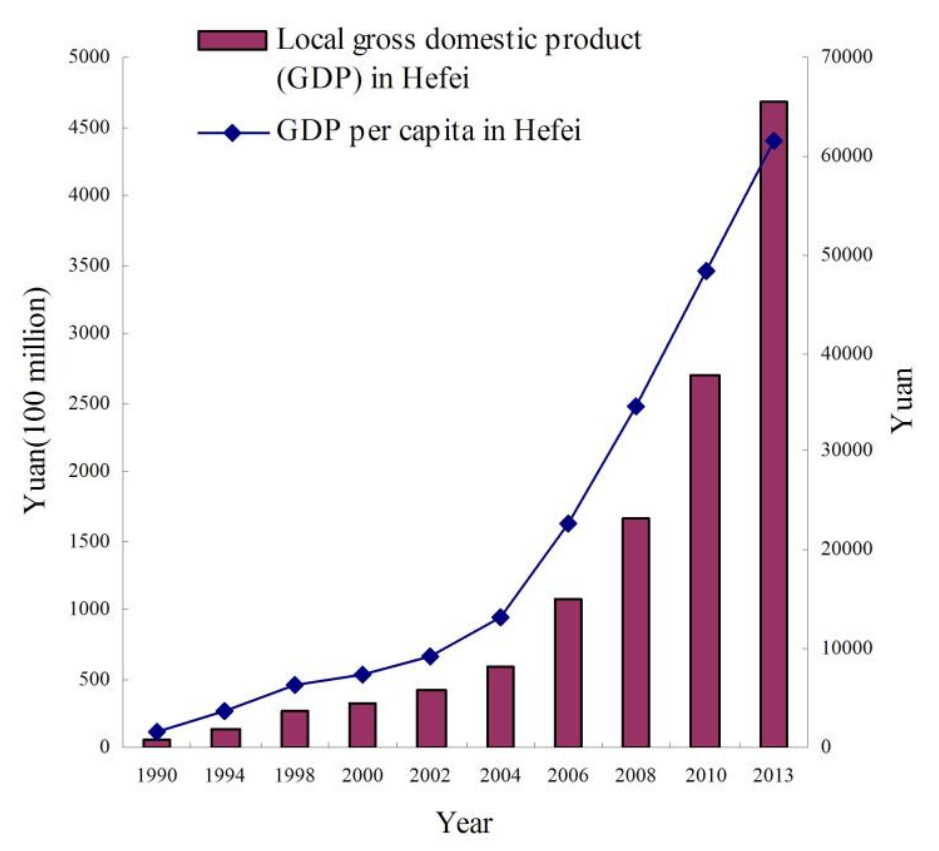

Fig. 6. Economic development in Hefei during 1990-2013

\subsubsection{Growth of Population and Construction Areas}

| Since the 1990s, the total population have showed a sharp increase from 386.42 $(10,000)$ in 1990 to $761.1(10,000)$ in 2013 (Figure 7 a). According to the population statistics from Anhui Statistical Information Net (http://www.ahtjj.gov.cn/tjj/web/index.jsp), there were totally 5,702 million registered permanent residents in 2010 of Hefei City from the sixth national population census. A total of 1.235 million $(27.65 \%)$ was increased in 10 years and the average increase was 0.124 million (about $2.47 \%$ ) per year compared to the fifth population census in 2000. With the rapid urbanization and accelerated development in Hefei, the number of registered permanent residents have been increasing. Consequently, more and more houses and traffic facilities will be required along with the population growth. According to the Anhui Statistical Yearbook 2014, the construction areas and the traffic land areas have significantly increased from 1990 to 2013 (Figure 7 b). Specifically, the total land for residential areas and mining was just $66,477.64(10,000)$ in 1990, but it reached 78,036.95 $(10,000)$ in 2000 and $364040(10,000)$ in 2013, respectively. Similarly, the traffic land area was just $13,593.15(10,000)$ in 1990 , but it reached $48,710(10,000)$ in 2013. At the same time, arable land areas have kept a decreasing trend in Hefei (Figure $7 \mathrm{~b}$ ). The total arable land areas was 507,868.42 $(10,000)$, and it decreased to $494,464.80(10,000)$ in 2000 and $336,025(10,000)$ in 2013. In more than 20 years, the arable land increased by $33.84 \%$. 


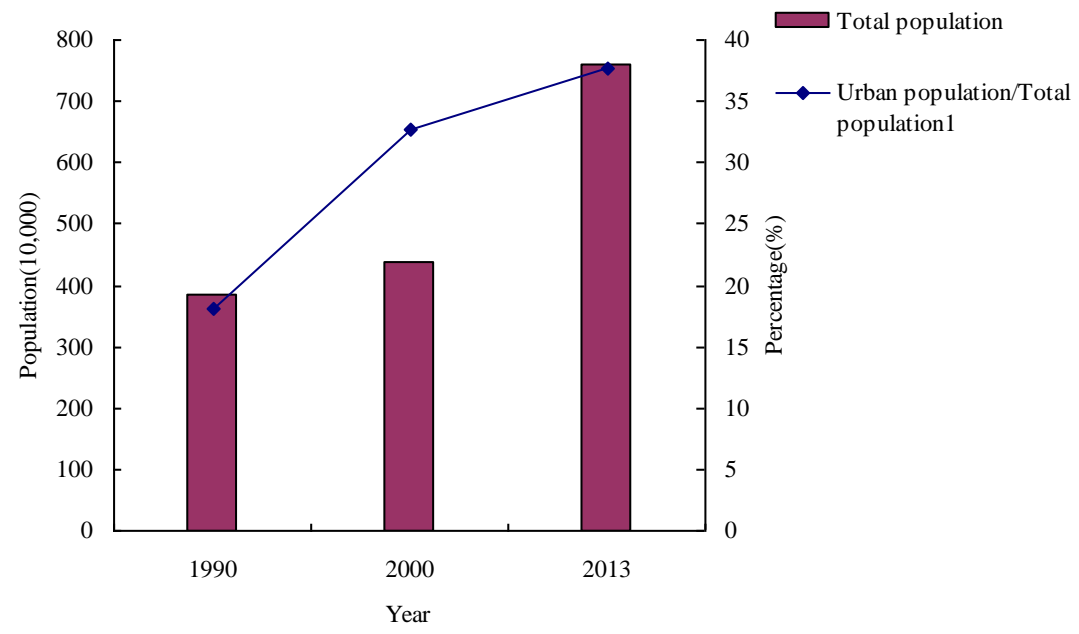

(a) Changes of population

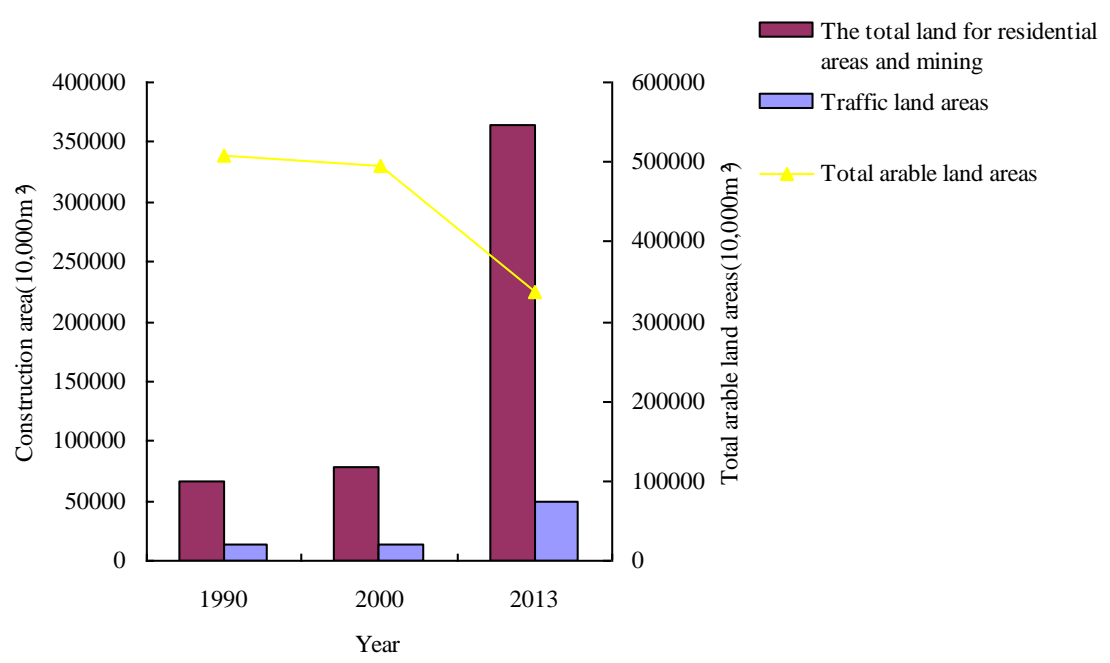

(b) Area changes of housing construction, traffic land and arable land

Fig.7. Changes of population and artificially changed areas in Hefei during 1990-2013

\section{Conclusions}

The landscape pattern of vegetation coverage can be dynamically explored based on multi-temporal remote sensing imagery. In general, the high vegetation coverage was significantly reduced, and the moderate-to-high degree had little changes, while low vegetation coverage and moderate vegetation coverage was significantly increased. Specifically, the high vegetation coverage in Hefei had decreased markedly from 
1990 to 2000 , but the situation had become better from 2000 to 2013 . Furthermore, the degree of landscape fragmentation had decreased from 1990 to 2013, while landscape diversity index and evenness index were higher, which showed that the distribution of each patch type was balanced and distributed relatively evenly in area. To find out the driving forces causing the changes of vegetation coverage, three types of driving factors were primarily discussed, including the economic development, growth of population and construction areas, and institutional policies. Multi-temporal remote sensing images are useful to monitor ecological changes of regional vegetation. Additionally, it is extremely necessary to find out the driving forces causing the changes of vegetation coverage.

\section{Acknowledgment}

The project was supported by Anhui Provincial Natural Science Foundation (No. 1408085QF126), the Open Research Fund of Key Laboratory of Digital Earth Science, Institute of Remote Sensing and Digital Earth, Chinese Academy of Sciences (No. 2014LDE012), and the Leadership Introduction Project of Academy and Technology of Anhui University (No. 10117700024).

\section{References}

1. Aurelia Bengochea- Morancho. A hedonic valuation of urban green areas [J]. Landscape and Urban Planning, 2003, 66, 35-41.

2. Junmei Tang, Chen Fang, Stuart S. Schwartz et al. Assessing spatiotemporal variations of greenness in the Baltimore-Washington corridor area [J]. Landscape and Urban Planning, 2012, 105, 296-306.

3. Zhaoning Gong, Huili Gong, Xiaojuan Li et al. Ecological environment effect analysis of Wetland change in Beijing region using GIS and RS [C]// Urban Remote Sensing Event, 2009 Joint. IEEE, 2009, 1-7.

4. Virginia H. Dale. The relationship between land-use change and climate change [J]. Ecological Applications, 1997, 7, 753-769.

5. Eugenia Kalnay, Ming Cai. Impact of urbanization and land-use change on climate [J]. Nature 2003, 423, 528-531.

6. Junmei Tang. Spatial analysis and temporal simulation of landscape patterns in two petroleum-oriented cities [J]. IEEE Journal of Selected Topics in Applied, 2009, 2, 54-60.

7. Griffith J A, Trettin C C, O'Neill R V. A Landscape Ecology Approach to Assessing Development Impacts in the Tropics: A Geothermal Energy Example in Hawaii [J]. Singapore Journal of Tropical Geography, 2002, 23(1):1-22(22).

8. Lili Yin, Hao Chen, Wei Li. Multi-scale analysis of landscape pattern of Hunan Province $[\mathrm{C}] / /$ Earth Observation and Remote Sensing Applications (EORSA), 2014 3rd International Workshop on. IEEE, 2014:309-313.

9. Baofa Peng, Yueli Hu. A study in stability of the regional land-use landscape pattern[C]// 2011 International Conference on Remote Sensing, Environment and Transportation Engineering. 2011, 1903-1906. 
10. Junmei Tang, Jianwu Tang. Linking Spatial Pattern and Biophysical Parameters of Urban Vegetation by Multitemporal Landsat Imagery [J]. Geoscience \& Remote Sensing Letters IEEE, 2013, 10(5):1263 - 1267.

11. Lin Liu, Bo Yao. Monitoring vegetation-cover changes based on NDVI dimidiate pixel model [J]. Transactions of the Chinese Society of Agricultural Engineering, 2010, 26, 230234.

12. Zhaoning Gong, Huili Gong, Xiaojuan Li et al. Dynamic monitoring of vegetation coverage in Shangri-La county of northwest Yunnan based on MODIS-NDVI [C]// International Conference on Geoinformatics. IEEE, 2013, 1-5.

13. Shupeng Chen. Study of information mechanism Remote Sensing (First Edition) [M]. Guangxi: Guangxi Education Press, 1998, 175-185(in Chinese).

14. Ming Wang, Wentao Yang, Peijun Shi et al. Diagnosis of Vegetation Recovery in Mountainous Regions After the Wenchuan Earthquake [J]. Selected Topics in Applied Earth Observations \& Remote Sensing IEEE Journal of. 2014, 7, 3029-3037.

15. Pengxin Wang, Xiaowen Li, Jianya Gong et al. Vegetation temperature condition index and its application for drought monitoring [C]// Geoscience and Remote Sensing Symposium. 2001.

16. Adams J E, Arkin G F. A Light Interception Method for Measuring Row Crop Ground Cover [J]. Soil Science Society of America Journal, 1977, 4, 789-792.

17. Catherine Leprieur, Michel M. Verstraete, Bernard Pinty. Evaluation of the performance of various vegetation indices to retrieve vegetation cover from AVHRR data [J]. Remote Sensing Review, 1994, 10, 265-284.

18. Zribi M, Le Hégarat-Mascle S, Taconet $\mathrm{O}$ et al. Derivation Of Wild Vegetation Cover Density In Semi-Arid Regions: Ers2/Sar Evaluation [J]. International Journal of Remote Sensing, 2003, 24(6), 1335-1352.

19. R. V. O'Neill, J. R. Krummel, R. H. Gardner et al. Indices of landscape pattern [J]. Landscape Ecology, 1988, 1(3), 153-162.

20. Xinqi Zhen. Landscape spatial analysis technology and application (First Edition) [M]. Beijing: science press, 2010, 93-147(in Chinese).

21. Jones K B, Wickham J D, O'Neill R V et al. Monitoring Environmental Quality at the Landscape Scale [J]. Bioscience, 1997, 47, 513-519.

22. HongJian Zhou, Jingai Wang, Yaojie Yue et al. Research on spatial pattern of humaninduced vegetation degradation and restoration:a case study of Shaanxi Province [J]. Acta Ecologica Sinica, 2009, 29(9), 4847-4856.

23. Genxu Wang, Yibo Wang, Kubota Jumpei. Land-Cover Changes And Its Impacts On Ecological Variables In The Headwaters Area Of The Yangtze River, China [J]. Environmental Monitoring \& Assessment, 2006, 120(1-3), 361-385.

24. George C.S Lin, Samuel P.S Ho. China's land resources and land-use change: insights from the 1996 land survey. Land Use Policy, 2003, 20, 87-107. 